\title{
OS DESAFIOS DO COTIDIANO EDUCACIONAL: O CASO DA EDUCAÇÃO FÍSICA
}

\author{
Marta Nascimento Marques* \\ Rodrigo de Rosso Krug** \\ Hugo Norberto Krug*** \\ Victor Julierme Santos da Conceição ${ }^{* * * *}$
}

Resumo: Este estudo teve como objetivo identificar e analisar os desafios percebidos pelos professores de Educação Física no cotidiano de suas práticas pedagógicas na escola. O caminho metodológico adotado seguiu os pressupostos da abordagem qualitativa do tipo estudo de caso. O campo de estudo foi uma escola pública de Santa Maria, RS, tendo as informações coletadas por meio de uma entrevista semiestruturada, realizada com três professores de Educação Física do ensino fundamental. Para analisar as informações coletadas, foi utilizada a análise de conteúdo. Concluímos que os principais desafios encontrados são a falta de espaço físico e material, a desvalorização da Educação Física, a falta de união e companheirismo entre os professores, os baixos salários, as limitações quanto à maneira de o professor desenvolver suas aulas, a indisciplina e violência entre os alunos e as dificuldades de não disporem de tempo para refletir e trocar experiências.

Palavras-chave: Educação Física. Desafios. Prática pedagógica.

\footnotetext{
"Mestre em Educação pela Universidade Federal de Santa Maria (UFSM); Professora de Educação Física da rede de ensino do Estado do Rio Grande do Sul; Especialista em Esporte Escolar pela Universidade de Brasília (UnB); martinhanm@yahoo.com.br

** Mestre em Ciências do Movimento Humano pela Universidade do Estado de Santa Catarina (UDESC); Especialista em Educação Física Escolar pela Universidade Federal de Santa Maria (UFSM); Doutorando em Ciências Médicas na Universidade Federal de Santa Catarina (UFSC); rodkrug@bol.com.br

**** Doutor em Educação pela Universidade Estadual de Campinas e pela Universidade Federal de Santa Maria (UNICAMP/UFSM); Doutor em Ciência do Movimento Humano pela Universidade Federal de Santa Maria (UFSM); Professor do Programa de Pós-Graduação em Educação Física (Mestrado) do Centro de Educação Física da Universidade Federal de Santa Maria (UFSM); Av. Roraima, n. 1000, Cidade Universitária, Bairro Camobi, Santa Maria, RS; hnkrug@bol.com.br

**** Doutor em Ciências do Movimento Humano pela Universidade Federal do Rio Grande do Sul (UFRGS); Mestre em Educação pela Universidade Federal de Santa Maria (UFSM); Especialista em Ensino e Pesquisa do Movimento Humano pela Universidade Federal de Santa Maria (UFSM); Professor do Departamento de Educação Física da Universidade do Extremo Sul Catarinense (Unesc). Av. Universitária, 1105 Universitário, Criciúma, SC; victorjulierme@yahoo.com.br
} 


\title{
The challenges of education every day: the case of Physical Education
}

\begin{abstract}
This study aimed to analyze the challenges perceived by Physical Education teachers in their everyday teaching practices in the school. The methodological tramp adopted followed the assumptions of a qualitative approach case study. The field study was a public school in Santa Maria, RS with the information collected through semi-structured interviews held with three physical education teachers in elementary school. To analyze the information collected was used to content analysis. It was concluded that the main challenges encountered are lack of physical space and equipment, depreciation of physical education, lack of unity and fellowship among teachers, low wages, limitations on the way the teacher developing lessons, indiscipline and violence among students and difficulties they have no time to reflect and share experiences.
\end{abstract}

Keywords: Physical Education. Challenges. Teaching practice.

\section{CONSIDERAÇÕES INTRODUTÓRIAS}

Em uma sociedade global, como a que vivemos atualmente, marcada pela diversidade de agentes e de contextos educativos, são vários os desafios com os quais as escolas, os professores e os alunos se confrontam. Segundo Marques (2011), a Educação Física nos dias atuais se faz presente como uma disciplina de grande importância no currículo escolar e também de vasta abrangência, necessitando, assim, ser analisada de modo diferenciado pelos docentes e pela sociedade em geral. Nesse sentido, Marques et al. (2009) colocam que a Educação Física se faz presente no contexto escolar com o objetivo de educar o aluno, auxiliando na construção de valores, no desenvolvimento de suas potencialidades motoras, cognitivas, afetivas, sociais, enfim, com a intenção de formar bons cidadãos. Porém, para que aconteça essa formação de qualidade, é preciso empenho e responsabilidade por parte do Professor de Educação Física, procurando em sua prática pedagógica considerar uma ampla visão de mundo, isto é, visão de homem e sociedade, para poder responder a questões, como: que tipo de aluno e sociedade quer formar? Para que sociedade esse aluno vai ser formado?

Entretanto, frente a tais preocupações e procurando fazer uma formação de qualidade, o professor de Educação Física, em sua prática pedagógica no cotidiano escolar, enfrenta "[...] vários desafios que dificultam e impedem que atinja sucesso em sua atuação." (LIMA, 2012, p. 158, grifo nosso). 
Dessa forma, convém destacar que consideramos desafio a ação ou o efeito de desafiar, isto é, a possibilidade de enfrentamento dos problemas e/ou dificuldades definidos(as) como um obstáculo, uma situação difícil ou ainda algo de difícil solução.

Assim, nesse direcionamento de ideia, Lima (2012) destaca que os professores convivem com inúmeros desafios no cotidiano de sua profissão.

Consequentemente, considerando que esses desafios podem interferir direta ou indiretamente na prática pedagógica do professor de Educação Física, construímos a seguinte problemática norteadora: quais os desafios percebidos pelos professores de Educação Física no cotidiano de suas práticas pedagógicas na escola?

A partir desse questionamento, o objetivo geral foi analisar os desafios percebidos pelos professores de Educação Física no cotidiano de suas práticas pedagógicas na escola.

A realização deste estudo se justificou pela tentativa de compreender os desafios inerentes à docência dos professores de Educação Física escolar, bem como auxiliar na melhoria da qualidade da prática pedagógica desses professores na escola. Para isso, pretendemos que os debates avancem sobre as informações apontadas no artigo, e que sejam elementos de construção teórico-argumentativa sobre contextos de ensino-aprendizagem, no campo da Educação Física, fomentando outras investigações e reflexões nos bancos universitários que tratam sobre a formação de professores. Ainda, destacamos que a multiplicidade e a complexidade dos processos de ensino e de aprendizagem da Educação Física tenham relevância para a construção de uma visão partilhada entre professores e demais agentes da comunidade escolar, contribuindo para a prática educativa do Professor de Educação Física.

\section{PROCEDIMENTOS METODOLÓGICOS}

Este estudo caracterizou-se como qualitativo, o qual tem se tornado cada vez mais comum e surge como alternativa metodológica para estudos voltados à educação. Segundo Triviños (1987), a pesquisa qualitativa não estabelece separações rígidas entre a coleta de informações e as interpretações delas, o estudo desenvolve-se como um todo, pois todas as partes estão relacionadas.

A pesquisa qualitativa desenvolve finalidades muito importantes na Educação Física escolar, como: oferecer aos professores uma maneira diferente de pensar, ressignificar e situar sua prática em um contexto social bastante amplo; sugerir formas variadas de discutir sobre seus conhecimentos; e, oportunizar a eles que explorem seus anseios e opiniões (MOLINA NETO; MOLINA, 2010). 
A forma assumida (tipo) de pesquisa foi o estudo de caso, já que Martins (2006, p. 9) afirma que "[...] o estudo de caso possibilita a penetração em uma realidade social, não conseguida plenamente por um levantamento amostral e avaliação exclusivamente quantitativa."

De acordo com Cauduro (2004), por meio do estudo de caso é possível que se realize um estudo profundo de um ou de poucos objetos, ou de pessoas a fim de que se consiga um amplo e detalhado conhecimento sobre eles.

Um caso pode representar um mundo no qual muitos casos se sintam representados. Um caso constitui uma voz que pode, em um instante determinado, condensar as tensões e os desejos de outras tantas vozes silenciadas. (MOLINA, 2010, p. 104).

Para coletar as informações, utilizou-se a entrevista semiestruturada, já que é um dos métodos que mais facilita a interação com o campo de estudo e é considerada um dos instrumentos básicos e de grande eficácia, desde que haja habilidade por parte do entrevistador. De acordo com Triviños (1987, p. 146) ela

[...] parte de certos questionamentos básicos, apoiados em teorias e hipóteses, que interessam à pesquisa, e que, em seguida, oferece amplo campo de interrogativas, fruto de novas hipóteses que vão surgindo, à medida que se recebem as respostas do informante. Desta maneira, o informante, seguindo espontaneamente a linha de seu pensamento e de suas experiências dentro do foco principal colocado pelo investigador, começa a participar na elaboração do conteúdo da pesquisa.

Também a utilização dessa técnica foi de grande valia porque permitiu a criação de um clima de interação recíproca entre entrevistador e entrevistado, possibilitando fluir naturalmente as informações.

Participaram do estudo três professores de Educação Física de uma escola pública de Santa Maria, RS. Para a escolha dos participantes, optou-se por professores em efetivo exercício da atividade docente no período da realização da entrevista e que tivessem mais de dez anos de carreira, por possuírem certa experiência profissional na disciplina de Educação Física. Também foi usado como critério o aceite e a disponibilidade para participar da investigação por parte dos professores de Educação Física, pois demandou a realização de alguns encontros para as entrevistas e, consequentemente, tempo disponível pelos professores.

Os participantes da investigação, designados por nomes fictícios para preservar as suas identidades, foram os seguintes: 
a) Professora Violeta: licenciada em Educação Física pela Universidade Regional da Campanha, Campus de Bagé, concluiu sua formação inicial em 1990. Após quase dois anos de formada, realizou concurso público promovido pelo Governo estadual do Rio Grande do Sul, para o cargo de Professora de Educação Física. Foi aprovada, porém, demorou um pouco para ser nomeada. Atualmente, desenvolve suas atividades docentes como Professora de Educação Física, para os anos finais do Ensino Fundamental e do Ensino Médio, em escola da rede estadual de ensino, em Santa Maria, há 17 anos. Seu regime atual de trabalho é de 40 horas;

b) Professora Rosa: licenciada em Educação Física pelo Centro de Educação Física e Desportos da Universidade Federal de Santa Maria e concluiu sua graduação em 1985. Possui especialização em Educação Física e mestrado em Educação pela mesma universidade. Após alguns anos trabalhando em academia, prestou concurso público promovido pelo Governo estadual do Rio Grande do Sul, para o cargo de Professora de Educação Física. Foi aprovada e logo começou a exercer a profissão. Atualmente, desenvolve suas atividades docentes como Professora de Educação Física, para os anos finais do Ensino Fundamental e do Ensino Médio, em escola da rede estadual de ensino, em Santa Maria, há 17 anos. Seu regime atual de trabalho é de 40 horas;

c) Professor Lírio: licenciado em Educação Física pelo Centro de Educação Física e Desportos da Universidade Federal de Santa Maria e concluiu sua graduação em 1989. Possui especialização em Educação Física pela mesma universidade. Logo que se formou não atuou diretamente em escolas, mas como preparador físico. Já em 1998 ingressou no magistério público estadual como Professor contratado. Após isso, prestou concurso público promovido pelo Governo estadual do Rio Grande do Sul, para o cargo de Professor de Educação Física. Atualmente, desenvolve suas atividades docentes como Professor de Educação Física, para os anos finais do Ensino Fundamental, em escola da rede estadual de ensino, em Santa Maria, há 12 anos. Seu regime atual de trabalho é de 40 horas.

Já o campo de estudo teve como palco uma escola da rede estadual de ensino do Rio Grande do Sul, localizada na zona periférica (Bairro Cohab Santa Marta) da 
cidade de Santa Maria, RS. A escola foi fundada em 1980 e possui desde a Educação Infantil até o Ensino Médio. Funciona em três turnos, sendo pela manhã anos iniciais do Ensino Fundamental, à tarde e à noite os anos finais do Ensino Fundamental e o Ensino Médio. Possui aproximadamente 2.000 alunos, 40 funcionários e 110 professores, destes, seis são professores de Educação Física. Os alunos integrantes da escola são de classe baixa, a maioria não possui uma boa estrutura familiar e convive com sérios problemas sociais, como drogas, violência, etc. A escola não apresenta uma boa estrutura física para a realização das aulas de Educação Física, pois possui apenas uma quadra descoberta, uma área de grama e o pátio da escola. Os materiais, como rede, bolas de vôlei, de futsal e handebol também são poucos. O horário das aulas de Educação Física acontece no contraturno, isto é, no turno inverso às outras disciplinas curriculares, e as turmas de alunos para a Educação Física são mistas. A maioria dos alunos é assídua e participa das aulas de Educação Física com bastante entusiasmo, demonstrando gosto pela disciplina, com exceção dos alunos do noturno, porque muitos deles trabalham, são amparados pela lei (dispensa) e os que praticam são bastante infrequentes. Na questão do planejamento, os professores de Educação Física procuram se guiar pelo Projeto Político-Pedagógico da escola, cada um planejando suas próprias aulas. Realizam reuniões semanais para assuntos gerais, mas nem sempre há a participação de todos. Não existem muitos momentos de planejamento e trocas entre os professores de Educação Física, pois cada um está mais preocupado em cumprir seu horário e ministra as suas aulas. Normalmente, não se encontram porque trabalham em turnos diferentes.

Para este estudo foi significativo o uso da análise de conteúdo para a interpretação das informações, pois esta, segundo Martins (2006, p. 35), “[...] é uma técnica de grande eficácia, porque busca a essência da substância de um contexto nos detalhes dos dados e informações disponíveis".

Triviños (1987) coloca que a análise de conteúdo representa um conjunto de técnicas para analisar comunicações, que buscam desvelar, por meio de procedimentos sistemáticos e objetivos de descrição do conteúdo das mensagens, indicativos que possuem a inferência de conhecimentos relativos às condições reais das mensagens. Salienta, ainda, que a análise de conteúdo apresenta três fases, sendo elas: a) A pré-análise: refere-se à organização do material; b) A descrição analítica: o material coletado é submetido a uma análise sistemática e aprofundada embasada no referencial teórico do estudo. Os procedimentos realizados nessa fase são a codificação, a classificação e a categorização; c) A interpretação referencial: as análises realizadas até essa fase são submetidas a uma reflexão mais intensa, buscando revelar elementos ocultos. 
No que se refere aos aspectos éticos desta pesquisa, destacou-se que ela foi aprovada pelo Comitê de Ética em Pesquisa com Seres Humanos da Universidade Federal de Santa Maria (CAAE n. 0232.0.243.000/10).

\section{OS DESAFIOS QUE FAZEM PARTE DO CONTEXTO DA EDUCAÇÃO FÍSICA ESCOLAR}

De acordo com Lima (2012), ao mesmo tempo que se torna o centro dos discursos das reformas educativas, e é considerado fundamental no processo educativo, o sujeito ator e autor, imprescindível para a melhoria da qualidade do ensino, também enfrenta no exercício da docência vários desafios que dificultam e impedem que atinja sucesso em sua atuação.

Assim, segundo Marques (2011, p. 65, grifo nosso), fala:

[...] sobre os professores, em especial o professor de Educação Física, suas práticas educativas e a realidade vivida por esse no cotidiano escolar é uma confrontação com um grande leque de desafios, pois não é de hoje que o sistema educacional brasileiro vem desabando, acompanhado de uma crise de referências que estamos vivendo em termos de civilização e a Educação Física está fortemente envolvida por essa crise ou mesmo desvalorizada.

Dessa forma, no cotidiano escolar é grande a carga de queixas por parte dos professores, pois, conforme Vasconcellos (2007, p. 15), “[ [... no tempo atual, um professor que não tenha um nível razoável de angústia em relação à sua atividade, que não se sinta desacomodado, com certeza, não é um professor do tempo atual"!

Para Ghedin, Almeida e Leite (2008), o que muitas vezes, acontece, é que sobre o professor é colocada a responsabilidade de educar, de formar cidadãos e quando ocorre o fracasso escolar a culpa também é dele, no entanto, professores e alunos são vítimas de uma política educacional que não prioriza o desenvolvimento da educação. Os professores são vítimas ainda da falta de interesse da sociedade na construção de sua valorização profissional, por meio de salários dignos, formação continuada adequada, melhores condições físicas e materiais para as escolas.

De acordo com Libâneo (2006), cada vez se torna mais difícil para os professores assumirem os requisitos profissionais e éticos da sua profissão, diante dos baixos salários que recebem e da precária preparação profissional; eles são tomados por uma baixa autoestima que interfere na sua personalidade, dificultando, assim, qualquer atitude motivadora de mudança. Além disso, os programas de formação continuada que poderiam auxiliar e motivar os professores, quando existem, na maioria 
das vezes, são inadequados, não atendem aos seus anseios. Por isso, acabam se frustrando e perdendo o interesse pela busca da autoformação e o nível de expectativa de desenvolvimento pessoal e profissional cada vez diminui mais.

Ainda nesse embate, um dos sentimentos mais constantes que se encontra nos professores é a sensação de sufocação, sentem-se saturados diante de tantas tarefas e responsabilidades que precisam desempenhar frente às novas exigências curriculares e sociais que fazem parte do cotidiano escolar (PÉREZ GÓMEZ, 2001).

Nas entrevistas, os Professores Violeta, Rosa e Lírio deixaram transparecer que os diversos desafios que encontram no cotidiano escolar não diferem dos colocados pela literatura especializada. Entre eles foram relatados a desvalorização da Educação Física, os problemas de espaço físico e material, os baixos salários, que acabam desmotivando o professor para buscar mais, para superar algumas limitações quanto à maneira de desenvolver suas aulas. Também foram colocados por dois professores (Rosa e Lírio) desafios quanto ao relacionamento, indisciplina e violência entre os alunos, frutos dos valores da sociedade atual que acaba interferindo no trabalho e no desenvolvimento das aulas.

Nesse viés, Ghedin, Almeida e Leite (2008) deixam nítido que compreender os desafios da prática é uma tentativa de interpretar o modo de ser de cada professor no dia a dia do contexto escolar. Também colocam que é por meio das ações, pessoais ou institucionais, que o professor irá projetar o seu modo de ser, na tentativa de cada vez ser mais e melhor.

Nesse sentido, procurou-se entender, mediante a fala da Professora Violeta, alguns desafios que fazem parte de sua prática cotidiana:

Bom, para eu dar aula [...] os desafios que eu encontro mais é
a falta de material, a falta de espaço físico que nós temos aqui
dentro de nossa escola, temos vários professores e quase dois
mil alunos, sem espaço nenhum quase [...] então a gente tem
que se virar com aquilo que tem, mas o que acontece é que o
trabalho poderia ser muito melhor se a gente tivesse um bom
espaço e material disponível, porque se eu continuo recebendo
duas bolas como é que eu vou fazer um trabalho educativo?
Como é que eu faço essa iniciação com o aluno se eu não te-
nho material disponível? Então eu tenho que dar aquela aulinha
mais ou menos e me sinto, às vezes, frustrada por causa disso,
mas o que é que eu posso fazer? É isso que acontece na maioria
das escolas. (Professora Violeta) (informação verbal).

Percebemos que o trabalho do profissional de Educação Física é dificultado, na maioria das vezes, por diversos fatores, como falta de materiais e espaço inadequado, desvalorização pela sociedade e por outros profissionais, etc. Porém, es- 
ses empecilhos não devem comprometer o trabalho dos professores, tampouco ser argumento para o seu comodismo com a carreira docente.

Krug, Beltrame e Menezes Filho (1998) e Farias, Shigunov e Nascimento (2001) afirmam que alguns dos fatores que interferem negativamente na prática pedagógica dos professores de Educação Física são a falta de materiais disponíveis para a realização das atividades e a falta de espaço físico adequado à prática, principalmente, nas escolas públicas, que é o caso deste estudo.

De acordo com Marques e Krug (2009), os principais problemas sentidos pelos professores de Educação Física no decurso de suas carreiras estão relacionados à falta de condições em termos físicos e materiais para o desenvolvimento das aulas de Educação Física, às dificuldades em organizar o processo de ensino-aprendizagem, ao número excessivo de alunos em aula, ao desajustamento dos programas, à atitude de passividade e/ou de não colaboração dos colegas, à inexistência de medidas adequadas ao controle do insucesso escolar, aos alunos indisciplinados com a falta de interesse e/ou concentração nas aulas e, ainda, a falta de acompanhamento da família, caracterizando uma desvalorização do trabalho do professor.

Além disso, Santini e Molina Neto (2005), a partir de um estudo com professores de Educação Física da rede de ensino municipal de Porto Alegre, RS, constataram que a quantidade de turmas, o número excessivo de alunos a atender, o número de horas dedicadas à prática pedagógica, bem como a falta de tempo para a qualificação desejada e necessária, vêm afetando tanto a qualidade de vida quanto a melhoria profissional dos professores.

Esses autores ainda colocam que vários professores dessa disciplina apresentam o relato sobre o fato de as aulas serem ministradas em espaço aberto, tornando a atividade sujeita às constantes avaliações de pais, alunos e colegas. Salientam o tamanho desconforto que isso gera e até mesmo em certos momentos acaba influenciando no próprio desempenho das aulas.

Conforme Darido e Neto (2005), também é comum observar a falta de privacidade existente nas aulas de Educação Física, pois o professor e os alunos quase sempre contam com espectadores em suas aulas, como pessoas da direção, funcionários da escola, alunos de outras turmas, pais, etc. Todos esses elementos, de alguma forma, interferem no desenvolvimento das aulas, muitas vezes, atrapalhando a concentração dos próprios alunos e isso acaba dificultando a prática pedagógica do professor. Já nas outras disciplinas isso não acontece, pois se pode manter a porta da sala fechada e ter mais privacidade para desenvolver o trabalho. 
Essa cultura escolar, para muitos dos professores de Educação Física, tornou-se cômoda e segura. Para outros ainda não, sendo frequente o professor sentir-se impotente diante dela e incomodado com essa rotina. Alguns analisam tais situações como obstáculos para que desenvolvam suas propostas pedagógicas. (DARIDO; NETO, 2005, p. 113).

Somos conhecedores dessa cultura escolar que por muito tempo acompanha as aulas de Educação Física e, como tal, analisamos como um descaminho, isto é, um aspecto negativo, pelo qual tudo se torna mais difícil de ser superado, inclusive a concretização da própria proposta pedagógica da disciplina de Educação Física. Por outro lado, o professor não pode se acostumar com essa cultura e deixar de lutar e buscar alternativas para que tal situação seja transformada e que suas práticas sejam de melhor qualidade sem muita interferência externa.

Nessa perspectiva, Pérez Gómez (2001) acrescenta que os docentes exercem um papel bastante reduzido na questão da tomada de decisões no sistema educativo, trabalham, muitas vezes, em um clima de isolamento, distanciamento ou até mesmo de rivalidade, perdendo as oportunidades de comunicação e de contribuir com seus conhecimentos e experiências. Dessa forma, aos poucos vão se tornando desmotivados e desvalorizados no ambiente escolar. Podemos observar tal posicionamento nas falas a seguir:

Acho que nós deveríamos ter mais ética profissional, nos prote-
ger e resolver nossos problemas entre nós, não ficar falando do
outro, ter mais união entre os professores, os colegas, principal-
mente na Educação Física, porque é muito comum nas escolas
comentarem que a Educação Física nunca se entrosa e os profes-
sores não possuem bom relacionamento, mas as outras discipli-
nas eu quase não vejo falar, eu acho que nós temos que ter mais
ética e nos unirmos mais como profissionais, é isso tá faltando.
[...] Atividades dentro da escola são muito poucas que a Educa-
ção Física atua, nós temos as interséries esse ano que agora sim
que existe uma maior socialização entre os professores, entre as
turmas e alunos, mas outras atividades eu sinto que o Profes-
sor de Educação Física, ele fica afastado, um pouco deixado de
lado [...] acho que a Educação Física até hoje ela ainda é deixa-
da um pouco de lado, ela não é tão valorizada como as outras
disciplinas. (Professora Violeta) (informação verbal).

Apesar de todas as dificuldades e empecilhos que o Professor de Educação Física enfrenta no seu cotidiano, ele ainda se sente desvalorizado, deixado de lado pela comunidade escolar, parece que a única utilidade e/ou competência que esse Professor possui é para dar aula. 
De acordo com Both e Nascimento (2009), o que vem ocorrendo é uma grande intensificação do trabalho docente, resultando em uma constante pressão com os professores na busca de inovações educacionais. Porém, na maioria das vezes, as próprias instituições educacionais não incentivam, nem apresentam as mínimas condições de trabalho para que possa acontecer essa busca, tampouco sua devida operacionalização no ambiente escolar.

Segundo Pérez Gómez (2001), são inúmeros os fatores que afligem a competência profissional do professor, emaranhando-o em uma sensação cada vez maior de insegurança, estresse e impotência diante dos problemas que encontra, tornando-se cada vez mais dependente e carente de iniciativas, à espera de determinações e recomendações da coordenação ou direção da escola.

Para tais constatações, conforme Libâneo (2006, p. 91), o diagnóstico é apenas um:

\begin{abstract}
Os problemas vão se reproduzindo em cadeia em cada nível de formação. As universidades formam mal os futuros professores, os professores formam mal os alunos. Poucas universidades brasileiras têm uma política definida em relação à formação de professores para o ensino fundamental e médio. Há um desinteresse geral dos Institutos e Faculdades pelas licenciaturas. Com isso, os professores saem despreparados para o exercício da profissão, com um nível de cultura geral e informação extremamente baixa, o que resulta num segmento de profissionais sem as competências pessoais e profissionais para enfrentar as mudanças gerais que estão ocorrendo na sociedade contemporânea.
\end{abstract}

Muitas mudanças vêm acontecendo no âmbito da educação e da cultura escolar, porém, esse processo ainda é bastante lento; mesmo que tais mudanças sejam positivas, elas demoram a aparecer e fazer a diferença no contexto educativo, o que acaba deixando o professorado sem expectativas e, muitas vezes, sendo divergentes às próprias mudanças.

De acordo com Krug (2004), está cada vez mais difícil o professor conseguir realizar mudanças significativas em sua prática pedagógica, pois ele se encontra em um contexto sociopolítico desfavorável, além do mais, não tem o mínimo de dignidade humana para exercer suas práticas, com isso, não consegue encontrar motivação para pensar suas aulas além dos manuais de ensino.

Sobre tais limitações em relação à prática pedagógica, podemos constatá-las nas falas da Professora Rosa:

Quando eu comecei a dar aula em São Martinho da Serra, que eu trabalhei a Educação Física dentro do horário como módulo. Quando chovia, aí tinha que trabalhar dentro da sala de aula 
com 30 alunos. Com outras turmas tendo aula na sala ao lado, aí tinha que propor um trabalho onde não podia ter muito barulho pra não atrapalhar e mesmo assim ter que desenvolver um trabalho. Então tu começas a ter dificuldades, ou tu crias outras possibilidades ou vai se podando e aí talvez eu não tenha criado grandes possibilidades nessa situação.

[...] Hoje na Educação Física eu vejo limitações sim, pois eu coloquei um plano pro meu trabalho e expus esse plano pros alunos, eles concordaram, mas eu vejo que se eles pudessem gostariam que fosse diferente [...] Eu sei, por exemplo, que têm alunos que gostariam de trabalhar vôlei o ano inteiro, outros gostariam de dança o ano inteiro ou gostariam de ter ginástica, mas como não é mais clubes, isso não é mais possível. Eu faço um trabalho com projeto extensão quartas séries, aí eu trabalho muito com brincadeiras, mas com a sétima série eu fiz uma proposta e, às vezes, eu me vejo tendo que questionar com eles a questão de relacionamento [...] acho que com a dança e a capoeira eu conseguia tematizar mais isso e agora fechado do jeito que está, eu tento, às vezes consigo, às vezes não. (Professora Rosa) (informação verbal).

O comentário da Professora Rosa diz respeito a algumas mudanças recentes que aconteceram no âmbito da Educação Física escolar na referida escola; tanto para os alunos quanto para os professores ainda são necessários alguns ajustes, pois até 2009 a Educação Física era trabalhada por meio de clubes, em que cada aluno podia optar por qual modalidade gostaria de participar, então, ele se inscrevia para uma modalidade com determinado professor e durante todo o ano era desenvolvido um trabalho voltado para determinado esporte. No entanto, após as mudanças, não existem mais os clubes e, consequentemente, os alunos não têm mais opção, as aulas de Educação Física são por série, meninos e meninas juntos e todos participam de todas as atividades e modalidades desenvolvidas nas aulas durante o ano letivo. Acerca disso, não houve muita aceitação pelos alunos, acarretando dificuldades no desenvolvimento do trabalho dos professores.

Sobre tais fatos, Darido e Neto (2005) destacam que diante das novas significações atribuídas à Educação Física já ultrapassa a ideia desta ser voltada unicamente para o ensino da parte motora, mas cabe muito mais ao professor problematizar, relacionar, interpretar e compreender com seus alunos todas as manifestações da cultura corporal, para que eles possam compreender o verdadeiro sentido e significado presentes nas práticas corporais. Assim, segundo as autoras:

O papel da Educação Física ultrapassa o ensinar esporte, ginástica, dança, jogos, atividades rítmicas, expressivas e conhecimento sobre o próprio corpo para todos, em seus fundamentos e técnicas (dimensão procedimental), mas inclui também os seus 
valores subjacentes, ou seja, quais atitudes os alunos devem ter nas e para as atividades corporais (dimensão atitudinal). E, finalmente, buscar garantir o direito do aluno de saber porque ele está realizando esse ou aquele movimento, isto é, quais conceitos estão ligados àqueles procedimentos (dimensão conceitual). (DARIDO; NETO, 2005, p. 76).

Na maioria das vezes, o que se observa é que na Educação Física, até mesmo pela sua trajetória histórica, o professor se preocupa bem mais em desenvolver os conteúdos de cunho procedimental e acaba esquecendo ou deixando de lado as dimensões atitudinal e conceitual que exercem grande importância, ou seja, auxiliam no complemento e entendimento dos procedimentos realizados.

A questão da indisciplina e a violência também é uma das dificuldades encontradas na Educação Física, porque isso está em todas as disciplinas, inclusive está na escola, está na sociedade. Então eu vejo que a escola não é a salvadora, ela é apenas mais uma instituição dentro da sociedade. Quando um aluno vem pra ti, ele traz toda uma família com ele, porque ele traz tudo o que ele vive, na história de vida desse guri, dessa guria, que, às vezes, tu tens que perguntar para poder entender, eu pergunto. (Professora Rosa) (informação verbal).

Diante dessa questão bastante vivenciada nos dias de hoje, em especial nas aulas de Educação Física, cada vez se torna mais evidente uma postura firme por parte da escola, como a do professor. Uma boa solução é que esses temas, "indisciplina" e "violência", sejam trabalhados, refletidos e analisados com os alunos e não que se fuja deles como se nada tivesse acontecendo. Levar em discussão atitudes e valores, quais são considerados éticos e não éticos, para que os alunos tenham consciência de tais comportamentos.

Sobre esse descaminho (aspecto negativo), é importante salientar que as aulas de Educação Física estão repletas de conflitos inerentes a qualquer forma de interação social, que emergem da interação do aluno com o meio social e cultural da aula. "Tais conflitos aparecem, principalmente, quando a aula conta com a resolução de problemas, o que implica não só conflitos, como também resistências, insatisfações e impasses que precisam ser superados pela intervenção acadêmica e social do professor.” (DARIDO; NETO, 2005, p. 110).

Darido e Neto (2005) destacam que para a mediação desses conflitos deve haver uma boa relação professor-aluno, a fim de que aconteça o diálogo, e o professor, no seu papel de mediador, precisa manter um ambiente de reflexão e de trocas para superar tais situações. 
Para isso, é necessário reavaliar as práticas pedagógicas inseridas em nosso meio, buscando compreendê-las melhor e, assim, engajados, procurar soluções para tais problemas, os quais não são culpa do professor, pois o aluno, a família e a sociedade também contribuem para que eles ocorram.

[...] a escola está sendo alvejada de outros segmentos que caem sobre ela. Tem a questão da mídia, que influencia muito os alunos, a questão familiar, a questão das drogas assim que tá de forma tal, então como lidar com isso? Como o professor vai encarar tudo isso? De que forma mudar essa situação? Ele vai ter que mudar o seu contexto dentro da escola para também mudar o seu aluno. Transformar esses descaminhos, fatores que somos alvejados diariamente em caminhos bons, de qualidade e isso depende da gente, de todos que estão envolvidos nessa caminhada. Não é fácil, mas também não é impossível, tem solução, basta tomar uma atitude. (Professor Lírio) (informação verbal).

O professor Lírio também pontua em sua fala preocupantes questões que estão cada vez mais presentes nas escolas e na sociedade como um todo.

Nessa perspectiva, Pérez Gómez (2001) coloca que os docentes e a própria instituição escolar estão frente ao grande desafio de construir um marco intercultural bastante amplo, no qual aconteça a integração de valores, ideias, tradições e costumes que assumam e fortaleçam a diversidade, a reflexão crítica e a tolerância. Todos esses elementos ajudarão no enfrentamento dos aspectos negativos impostos pela mídia e pela sociedade.

De acordo com Bracht (1992, p. 74), o professor, na sua prática, querendo ou não, é um veiculador de valores. "É nesse sentido que reside a vinculação da forma de ensino com seu conteúdo. A socialização do indivíduo ou da criança se dá exatamente através da internalização de valores e normas de conduta da sociedade a que pertence." Portanto, cabe à escola e ao professor promover tal socialização, realizando um trabalho que pontue tais situações para que o aluno possa distinguir o certo do errado.

Nesse sentido, segundo Arroyo (2000, p. 144),

[...] educar nada mais é do que humanizar, caminhar para a emancipação, a autonomia responsável, a subjetividade moral, ética [...] Nesses processos mais globais encontra maior relevância nosso ofício de mestres: democratizar o saber, a cultura e o conhecimento, conduzir a criança, jovem ou adulto a apreender o significado social e cultural dos símbolos construídos, tais como as palavras, as ciências, as artes, os valores, dotados da capacidade de propiciar - nos meios de orientação, de comunicação e de participação. 
Assim, a Educação Física, ao tratar dos elementos da cultura corporal, percebendo o movimento humano como historicamente construído e como linguagem, insere-se nessa densa perspectiva de educação proposta por Arroyo - que não guia as pessoas para a tolerância, mas para a emancipação.

Sobre essas questões, o Professor Lírio ainda acrescenta sua opinião. "Já a questão do professor, é preciso, digamos, buscar mais e ter um estímulo a mais [...] eu sinto que falta algo mais na Educação Física, só não estou conseguindo vê o que, se é mais atitude do professor, se é um buscar mais, independente do seu salário [...]" (Professor Lírio) (informação verbal).

A partir da colocação desse Professor, gostaríamos de salientar sobre a importância de o professor estar sempre na busca de aperfeiçoamento, por meio de leituras, pesquisas, cursos, etc. Só não se pode esperar que cursos, seminários ou encontros tragam "receitas prontas", ou seja, solução para seus problemas diários. Ao contrário, esses cursos devem servir de estímulo ao professor para que pense e reflita sobre as propostas teóricas e práticas e, a partir dessa reflexão, construa e experimente novos conhecimentos aliados aos que já possui, na tentativa de contribuir no seu trabalho e solucionar suas dificuldades (KRUG, 2004).

[...] a falta de tempo também é um fator negativo que ocorre na Educação Física, onde precisamos parar e conversar com os colegas: nós precisamos de um tempo, nós não temos tempo para nada, não estávamos conseguindo nos organizar, como é que tu estás? Quais tuas dificuldades? Eu não sei. Então falamos precisamos: de um TEMPO PRÁ DIALOGAR [...] (Professor Lírio) (informação verbal).

É reconhecido, ainda, que os professores não são bem remunerados e, portanto, trabalham mais do que suportam para manter um padrão de vida um pouco mais digno. Para isso, eles precisam trabalhar em várias escolas, precisando se deslocar de uma para outra e tudo isso em um tempo mínimo, o que, na maioria das vezes, impede que o professor tenha um maior envolvimento e dedicação com a comunidade escolar. Além disso, acaba sendo quase impossível a troca de experiências com os colegas, a qual é tão importante para o desenvolvimento de seu trabalho (DARIDO; NETO, 2005).

Diante desse cenário de desafios, condições de trabalho inadequadas, falta de espaço físico, materiais insuficientes para desenvolver as práticas, falta de tempo para refletir, dialogar e exercer a troca de saberes entre os professores, evidenciou-se a forte necessidade de produzir mudanças na prática dos professores e na própria escola. Assim, de maneira mais eficaz, seja possível buscar novos caminhos para o desenvolvimento profissional e também dos educandos. 
A reflexão é uma boa estratégia para se consolidar o reconhecimento da importância do professor e seu processo de profissionalização como variável decisiva para a compreensão do fenômeno educativo. Também a integração entre as práticas pedagógicas, a reflexão e a troca de conhecimentos teóricos irão constituir atividades docentes mais coerentes e críticas e, dessa forma, consolidarão em um processo contínuo de formação da identidade profissional docente (CRISTINO, 2007).

\section{CONSIDERAÇÕES FINAIS}

Ao finalizar este estudo, percebemos o quanto o cotidiano educacional é complexo e desafiador para os professores de Educação Física de uma escola pública.

Mediante a análise dos depoimentos dos professores estudados, identificamos comentários e reflexões destes quanto aos mais diversos desafios. Isto é, dificuldades e/ ou problemas em suas práticas pedagógicas que ultrapassaram as péssimas condições de trabalho, como a falta de espaços físicos e materiais destinados às aulas, os baixos salários, a falta de tempo para refletir e trocar experiências, avaliar as suas práticas mais detidamente, pela sobrecarga de atividades, passando pela indisciplina e violência dos alunos, mudanças curriculares e a influência do macrossocial. Mas, culminando na percepção de uma desvalorização profissional, esta podendo ser considerada um forte empecilho ao trabalho docente. Essa desvalorização ocorre principalmente em razão da falta de reconhecimento do Professor de Educação Física na atualidade.

Assim, um cotidiano educacional permeado de desafios provoca nos professores incertezas e insegurança que, certamente, interferem em suas práticas pedagógicas, provocando um sentimento de inoperância frente aos seus alunos e à sua tarefa profissional. Entretanto, também percebemos nas falas dos professores a revelação de um sentimento de luta e de resistência que os move diante dos desafios que encontram em seu contexto profissional e a esperança e vontade de transformá-los em caminhos (aspectos positivos) para uma Educação Física mais valorizada e de melhor qualidade.

Dessa forma, ao mesmo tempo que os professores estudados apontaram os desafios, percebemos um ponto de partida para se inferir uma mudança de perspectiva frente a eles: $O$ tempo para dialogar! Com tempo para dialogar, pode surgir um trabalho que possibilite a troca e a reflexão no ambiente escolar, a partir da visão de totalidade sobre os aspectos relevantes e imediatos do trabalho pedagógico.

Ressaltamos que o professor, ao refletir sobre o seu próprio fazer cotidiano, pode produzir novas atitudes, como construir novos conhecimentos, procurando sempre efetuar um diálogo entre a sua didática e a sua prática, tornando-se um mediador 
e proporcionando em suas aulas momentos de reflexões, que favoreçam espaço para respostas críticas do alunado.

Consequentemente, no direcionamento dessas constatações realizadas, pensamos que este trabalho pode se constituir influência para o enfrentamento e a superação ou, ainda, a amenização dos desafios que se colocam ao ensino e à aprendizagem da Educação Física na escola.

\section{REFERÊNCIAS}

ARROYO, M. G. Trabalho-educação e teoria pedagógica. In: FRIGOTTO, G. (Org.). Educação e crise do trabalho: perspectivas de final de século. 4. ed. Petrópolis: Vozes, 2000.

BARDIN, L. Análise de conteúdo. Lisboa: Edições 70, 1995. 225 p.

BOTH, J.; NASCIMENTO, J. V. Intervenção profissional na educação física escolar: considerações sobre o trabalho docente. Movimento, Porto Alegre, v. 15, n. 2 , p. 169-186, jun. 2009.

BRACHT, V. Educação física e aprendizagem social. Porto Alegre: Magister, 1992. $122 \mathrm{p}$.

CAUDURO, M.T. Pesquisa: a construção de um conhecimento. In: CAUDURO, M.T. (Org.). Investigação em Educação Física e esportes: um novo olhar pela pesquisa qualitativa. Novo Hamburgo: Feevale, 2004.

CRISTINO, A. P. da R. Um olhar crítico-reflexivo sobre a formação continuada de professores de Educação Física da rede municipal de ensino de Santa Maria (RS). 2007. 162 p. Dissertação (Mestrado em Educação)-Universidade Federal de Santa Maria, Santa Maria, 2007.

DARIDO, S. C.; NETO, L. S. O contexto da Educação Física na escola. In: DARIDO, S. C.; RANGEL, I. C. A. (Coord.). Educação Física na escola: implicações para a prática pedagógica. Rio de Janeiro: Guanabara Koogan, 2005.

FARIAS, G. O.; SHIGUNOV, V.; NASCIMENTO, J. V. Formação e desenvolvimento profissional dos professores de Educação Física. In: SHIGUNOV, V.; SHIGUNOV NETO, A. (Org.). A formação profissional e a prática pedagógica: ênfase nos professores de Educação Física. Londrina: Midiograf, 2001.

GHEDIN, E.; ALMEIDA, M. I.; LEITE, Y. U. F. Formação de professores: caminhos e descaminhos da prática. Brasília, DF: Líber Livro, 2008. 
KRUG, H. N.; BELTRAME, V.; MENEZES FILHO, F. dos S. Diagnóstico dos problemas da prática pedagógica dos professores de Educação Física da rede municipal de ensino de Santa Maria. In: SIMPÓSIO NACIONAL DE GINÁSTICA E DESPORTO, 17., 1998, Pelotas. Anais..., Pelotas: ESEF/UFPEL, 1998.

KRUG, H. N. Rede de autoformação participada como forma de desenvolvimento do profissional de Educação Física. 2004. 220 p. Tese (Doutorado em Ciência do Movimento Humano) - Universidade Federal de Santa Maria, Santa Maria, 2004.

LIBÂNEO, J. C. Adeus professor, adeus professora? Novas exigências educacionais e profissão docente. 9. ed. São Paulo: Cortez, 2006. 104 p.

LIMA, V. M. M. A complexidade da docência nos anos iniciais na escola pública. Revista Nuances: estudos sobre educação, Presidente Prudente, v. 22, n. 23, p. 151169, maio/ago. 2012.

MARQUES, M. N. Caminhos e descaminhos da prática pedagógica em Educação Física Escolar: um estudo de caso com professores de uma escola pública de Santa Maria-RS. 2011. 105 p. Dissertação (Mestrado em Educação)-Universidade Federal de Santa Maria, Santa Maria, 2011.

MARQUES, M. N. et al. Um olhar voltado para o percurso profissional dos professores de Educação Física: reflexões e perspectivas. In: SEMINÁRIO NACIONAL DE FORMAÇÃ̃ DE PROFESSORES, 3., 2009. Santa Maria. Anais..., Santa Maria: UFSM, 2009.

MARQUES, M. N.; KRUG, H. N. Os problemas sentidos no decurso da carreira de professores de Educação Física Escolar e a relação com os momentos de ruptura profissional. In: SIMPÓSIO NACIONAL DE EDUCAÇÃO FÍSICA, 29., 2009. Pelotas. Anais..., Pelotas: ESEF/UFPEL, 2009.

MARTINS, G. de A. Estudo de caso: uma estratégia de pesquisa. 2. ed. São Paulo: Atlas, 2006. $101 \mathrm{p}$.

MOLINA NETO, V.; MOLINA, R. K. Pesquisa qualitativa em Educação Física escolar: a experiência do F3P-EFICE. In: MOLINA NETO, V.; BOSSLE, F. (Org.). O ofício de ensinar e pesquisar na educação física escolar. 1. ed. Porto Alegre: Sulina Meridional, 2010. v. 1.

MOLINA, R. K. O enfoque teórico metodológico qualitativo e o estudo de caso: uma reflexão introdutória. In: MOLINA NETO, V.; TRIVIÑOS, A. N. S. (Org.). A pesquisa qualitativa na Educação Física: alternativas metodológicas. 3. ed. ver. e ampl. Porto Alegre: Sulina, 2010. v. 1. 
PÉREZ GÓMEZ, A. I. A cultura escolar na sociedade neoliberal. Porto Alegre: Artmed, 2001. 320 p.

SANTINI, J.; MOLINA NETO, V. A síndrome do esgotamento profissional em professores de educação física: um estudo na rede municipal de ensino de Porto Alegre. Revista Brasileira de Educação Física e Esporte, São Paulo, v. 19, n. 3, p. 209-222, 2005.

TRIVIÑOS, A. N. S. Introdução à pesquisa em ciências sociais: a pesquisa qualitativa em educação. São Paulo: Atlas, 1987. 175 p.

VASCONCELLOS, C. dos S. Para onde vai o professor? Resgate do professor como sujeito de transformação. 12. ed. São Paulo: Libertad, 2007. 205 p.

Recebido em: 26 de outubro de 2014 Aceito em: 24 de abril de 2015 
